\title{
Active Vibration Control of Laminated Composite Plates by using External Patches
}

\author{
N. S. Sunil Varma ${ }^{1}$, S. S. Vamsi Krishna ${ }^{2}$, Dr. Ramesh Babu Vemuluri* \\ School of Mechanical Engineering, VIT University. Vellore.
}

\begin{abstract}
The concept of suppressing vibrations caused by external or internal stimulus has been evolving from a long time and there have been several techniques to suppress these vibrations involving spring mass dampeners and inertial mass actuators but the technique of active vibration control is more efficient in its ability to reduce vibrations to great extent. The field applications that active vibration control can be employed in, are vast ranging from structures like automobile engines, vehicle chassis, to airplane wings. The key significant improvement in using this technique is that the actuatosr placed reduces the vibrations of all modal frequencies more efficiently compared to other techniques that are efficient only in suppressing high-frequency modes. The main points to be considered in this technique are the positioning, number and the size of actuator/patch. In this study we used ANSYS 15.0 to analyse the impact of patch position, size and number on the natural frequency and displacement of the actual host structure (in our case laminated composite plate) by observing the strain values and root occurrence in case of the host structure. We used Piezo ceramic as an actuator/patch to suppress vibrations. The positional influence is shown to have a profound impact on reducing host structure deformation to a significant extent. The Analysis we have done paves a way for using active vibration control technique efficiently; since it involves the study of all the key parameters that helps in attenuating the vibrations.

Keywords: Active Vibration Control; Piezoceramics; Attenuation; Actuator; Laminated composites.
\end{abstract}

\section{INTRODUCTION}

All structural components are usually prone to vibrational forces due to either internal or external forces (like engine vibration on car chassis or piston movements on ship engines) acting on them. Under natural frequency limits these vibrations on the components are permissible but if the vibrational frequencies reach the natural frequency limits the entire component fails. Leitmann (1994) [1] discussed several methods of controlling these vibrations like changing the masses or spring and dampener constants techniques of passive vibration control or using control schemes coupled with other factors in case of semi-active vibration control. In case of active vibration control sensor/actuator pairs collaborated with control algorithms are used to attenuate these vibrational forces. Active vibration can control vibrations over large ranges include lower modal frequencies. Trinidade et al. (2001) [2] proposed that damping is limited by weight and geometrical constraints and to control low frequency and amplitude vibrations piezo electric actuators are to paired with a proper control system for efficient vibration attenuation. Recent advancements in active vibration control involve latching patches made of piezoelectrics mainly (PZT, PI Ceramics) or PVDF etc onto surface of host structure. Ramkumar et al. (2009) [3] studied a box structure laminated composite by bonding PZT patches onto its surface and it was observed that the influence on natural frequency was significant when patches are latched onto the surface. Baillargeon and Senthil, (2005) [4] explained that piezoelectric actuators as usually poled in thickness direction, so if electric field is applied in thickness direction it results in a change in lateral dimensions of the actuator resulting in host structure deformation; and if the electric field is applied parallel to the poled direction it leads to normal strain which happens in case of piezoelectric extension actuators which are usually placed at extreme thickness positions of host structure. Bianchini (2008) [5] proposed that when compared to other damping materials piezoelectric materials have relatively high stiffness, so the impact they cause on the host structure is significant. Plenter and Abramovich, (1995) [6] proposed that piezoelectric copolymers such as PVDF can be used to design helical springs which acts as a sensor in determining ground roughness or damping forces. Chandrashekhara and Agarwal, (1993) [7] found that mass and stiffness of the piezoceramic patches has a significant influence on the transient response of the system. The durability and adaptability demands of structural components have a profound impact on creating structural components which have long life cycles. Recent studies and advancements usually point towards the development of smart structures. Smart structures are known for their effective attenuation of external force/pressure applied. They deploy the simple mechanism of employing 
sensor/actuator pairs in an effective way to reduce vibrations in host structure. The main problem in using sensor/actuator pairs is regarding their positional placement, size and number. Gupta et al. (2010) [8] proposed a technical review in which several criteria are reviewed which optimally effects the influence of positional placement of sensor/actuator pairs. The criterion involves maximizing modal forces/moments; deflection of host structure; energy dissipated; degree of controllability; degree of observability and minimizing spill-over effects and control effort. Peng et al. (1998) [9] using third order laminate theory proposed that for the maximum effectiveness of the sensor/actuator pairs they must be placed around high strain regions and away from low strain regions. Moreover, if the number of sensor/actuator pairs are more the more efficient is the shape control and vibration suppression. The number of sensor/actuator pairs can be usually modified based on the amount of attenuation required; but it has less significance compared to positional placement. Rafi and Sami, (2011) [10] proposed finite element model based on Reddy's third order laminate theory for a beam having both ends fixed and found that both the number and location of piezoelectric patches play an important role in shape control of the structure but the number of sensor/actuator pairs are not as critical as their positional placement criteria. Gandhi and Mevada, (2013) [11] proposed a finite element model based on third order theory for the active vibration control of composite beams with distributed piezoelectric sensors and actuators. Direct piezoelectric equation is proposed and damping effect on the composite beam involved actuators coupled with a negative velocity feedback control algorithm in a closed control loop. High/low stiffness as well as number of sensor/actuator pairs also impact the composite structure. Sensor/actuator pairs should be located away from low strain areas. There are several control laws which are administered in case of active vibration control. Trindade et al. (2015) [12] performed an experimental study on design of piezoelectric sensors based on size and shape and their geometric distribution. Moreover, control laws like direct velocity feedback and positive velocity feedback are implemented to control specific vibration modes. Yaman et al. (2002) [13] analysed positional placement and size of BM500 actuators on aluminium plate to suppress first two modes of vibration by using modal analysis by devising a $\mathrm{H}_{\infty}$ controller technique. Raja et al (2002) [14] proposed that application of Linear Quadratic Regulator/Independent Modal Space Control for sensing the damping induced by shear and extension bending actuators. The shear actuator performs well in controlling first three bending modes compared to that of the extension-bending actuator. Qiu et al.
(2007) [15] proposed that Positive Position Feedback(PPF) can be coupled with Proportional Derivative algorithm(PD) effectively to suppresses the first three modes of vibration. Omidi (2014) [16] proposed that Modified Positive Velocity Feedback(MPVF) control has significant advantage over PPF as it efficiently uses two parallel feedback controllers; one for displacement and the other for velocity. The latest advancements involve several factors to be considered while approaching the technical application of active vibration control. Varadrajan and Bhanusri, (2013) [17] pointed out that of the three parameters length, breadth and thickness that influence shape of any 3 dimensional object it is found that frequency is directly proportional to breadth and inversely proportional to length and thickness and hence have very less impact on frequency of the object. Daley et al. (2004) [18] proposed selective damping technique in case of marine parts which are usually prone to large vibrations due to heavy moving parts; this selective damping technique can be used to attenuate residual forces and the secondary sources of vibration are also attenuated. Huang and Shen, (2004) [19] explained that material properties of Functionally Graded Material(FGM) are graded thermally whereas normal piezoelectric layers are graded thermally independent. The results show that temperature field and the volume fraction distribution have a significant effect but control voltage has very less impact on dynamic response of FGM plates. Pereira et al. (2014) [20] proposed that Inertial-mass actuators have been shown to be a viable technique to mitigate vibrations, allowing structures to satisfy vibration serviceability limits. Multi-input and Multioutput vibration control of pedestrian structures coupled with modifying performance index (PI) is used simultaneously to obtain the sensor/actuator placement. The above studies show that active vibration has immense applications and more effective way of mitigating vibrations. Even though individual studies above discuss on the positioning of the patches on various host structures the study in laminated composites is limited and that too specifically in obtaining the perfect methodology of positioning the piezoelectric patches, and moreover the number of patches and the dimensional influences are overlooked. So in this study we discuss about active vibration control study on laminated composite plates based on positional influence, dimensional influence and the numerical influence of patches.

\section{ANALYSIS OF LAMINATED COMPOSITE PLATE}

2.1 Process of Active Vibration Control: Active vibration control involves modification of host structure surface by applying sensor/actuator pairs onto the surface. In our case host structure is made of 
Aluminium and instead of using sensor/actuator pair we test the structural stability after applying patches/actuators made of PI ceramic. The application process of the patch depends upon identifying the high strain regions and applying them over there. Usually, the patches should be applied not to the exact extent of strain area but it should be optimally around the strain areas.

2.2 Constraints of Active Vibration Control: Constraints of Active Vibration Analysis: Constraints involve the positioning of patches, the dimension of patches and number of patches. Positioning of patches is to be done usually at the root of the host structure that is at the position where initial strain appears to develop. The dimension of patches and number of patches are usually interdependent and based on the property of the patch. If a patch has more modulus of elasticity the dimension and the number can be minimal and same as in the case of low modulus of elasticity the number and dimension should be maximum and distributed based on initial stress distribution.

2.3 Validation: Our validation is to test the process of the methodology involved in finding out whether the patches laid can lower the natural frequency limits of the host structure.

Host structure material: Aluminium flat plate $\mathrm{Al} 1050$ Actuator/patch material: BM500 type piezoelectric actuators from literature [13]

Table 1. Material properties of host structure and patch from literature

\begin{tabular}{|c|c|c|}
\hline $\begin{array}{c}\text { Material } \\
\text { Properties }\end{array}$ & $\mathrm{Al} 1050$ & BM 500 \\
\hline $\begin{array}{c}\text { Young's } \\
\text { Modulus }\end{array}$ & $6.9 \times 10^{10} \mathrm{~Pa}$ & $2.12 \times 10^{11} \mathrm{~Pa}$ \\
\hline Poisson's Ratio & 0.33 & 0.3 \\
\hline Density & $2710 \mathrm{~kg} / \mathrm{m}^{3}$ & $7650 \mathrm{~kg} / \mathrm{m}^{3}$ \\
\hline
\end{tabular}

Table 2. Comparison of first three modal frequency values from ANSYS analysis to literature values.

\begin{tabular}{|c|c|c|}
\hline $\begin{array}{c}\text { ANSYS } \\
\text { Analysis Data } \\
\begin{array}{c}\text { Frequency } \\
{[\mathrm{Hz}] \text { values }}\end{array}\end{array}$ & $\begin{array}{c}\text { Actual } \\
\text { Experimental } \\
\text { Data from } \\
\text { literature } \\
\text { Frequency }[\mathrm{Hz}] \\
\text { values }\end{array}$ & $\begin{array}{c}\text { Percentage } \\
\text { Difference }\end{array}$ \\
\hline 11.25 & 11.88 & 5.30 \\
\hline 37.342 & 41.47 & 9.95 \\
\hline 72.08 & 71.62 & 1.00 \\
\hline
\end{tabular}

\section{Modal frequency diagrams:}

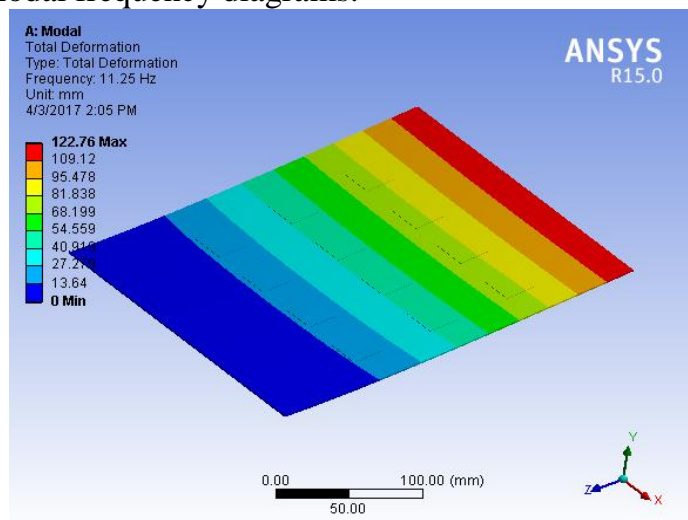

Fig. 1 Mode 1

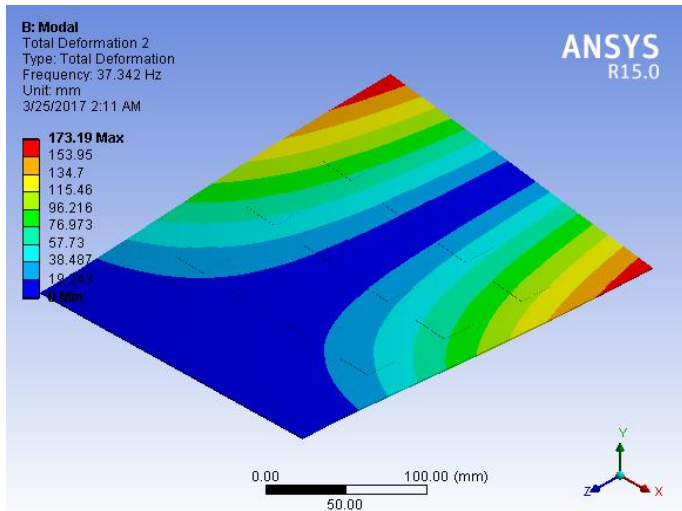

Fig. 2 Mode 2

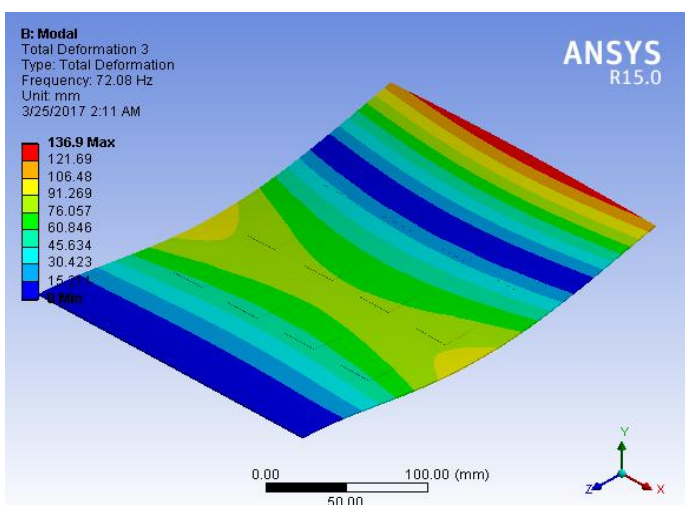

Fig. 3 Mode 3

\subsection{Laminated Composite Plate Analysis}

\section{Parameters:}

1. Patch Dimensions: $25 \times 25 \times 0.5 \mathrm{~mm}, 50 \times 50 \times 0.5$ $\mathrm{mm}, 75 \times 75 \times 0.5 \mathrm{~mm}$

2. Host structure Dimensions: 300x300x3 m. 
Table 3. Material Properties of Problem involving laminated composites and ceramics.

\begin{tabular}{|c|c|c|}
\hline $\begin{array}{c}\text { Material } \\
\text { Properties }\end{array}$ & $\begin{array}{c}\text { Laminated } \\
\text { Composite Plate }\end{array}$ & $\begin{array}{c}\text { PI ceramic } \\
\text { Patch }\end{array}$ \\
\hline Young's & E1 $=39.51 \mathrm{GPa}$ & $26.2 \mathrm{GPa}$ \\
Modulus & $\mathrm{E} 2=9.08 \mathrm{GPa}$ & \\
\hline Poisson's Ratio & $\mathrm{V} 12=0.258$ & 0.3 \\
& $\mathrm{~V} 23=0.49$ & \\
& $\mathrm{~V} 31=0.56$ & \\
\hline Density & $1925.9 \mathrm{kgm}^{-3}$ & $7650 \mathrm{kgm}^{-3}$ \\
\hline
\end{tabular}

\section{RESULTS AND DISCUSSION}

3.1 Analyzing the Laminated Composite plate based on the number of Actuators/Patches:

In this case, the laminated composite plate is studied based on the number of patches positioned on its surface. Our study includes $25 \times 25 \times 0.5 \mathrm{~mm}$ patches of 1 to 4 in number. The ANSYS analysis shows that as the number of patches increases the deflection is considerately reduced. In the case of lower modes, the decrease is more significant than compared to higher frequency modes. Upon increasing the number of patches such that their cross-sectional area is equal to that of the plate/structure the number of patches has less significance since more patches when positioned leads to a complete attenuation of the plate/structure and it starts bending in opposite direction. Along with the number of patches, the position should also be properly selected. The number influence of patches has been more significant in attenuating the vibrations in the laminated composite plate for lower frequency modes.

Positional Placement for 1,2,3 and 4 patches:

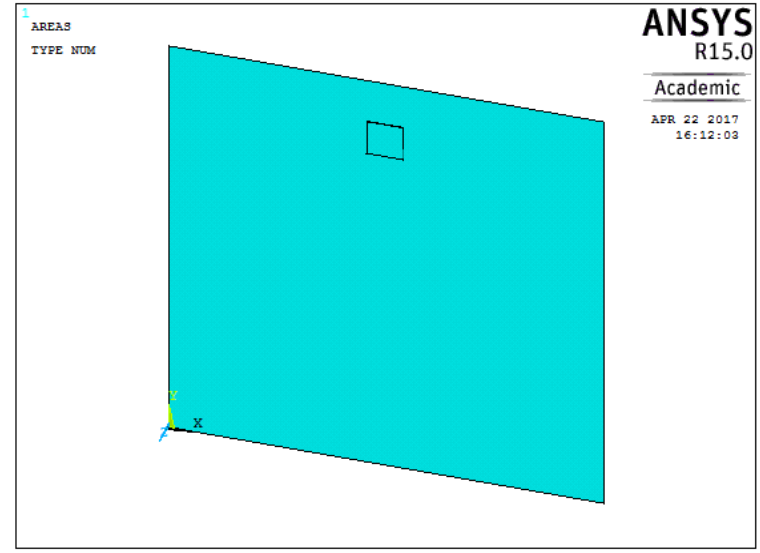

Fig. 4 Positioning of 1 patch

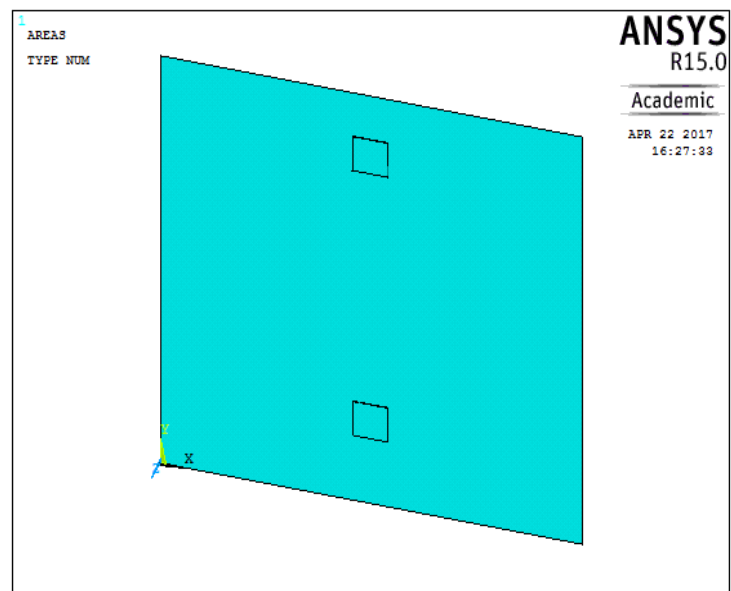

Fig. 5 Positioning of 2 patches

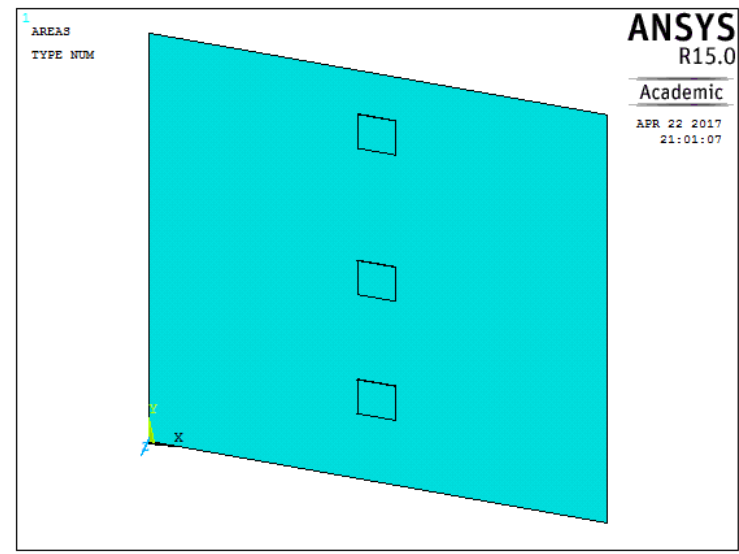

Fig. 6 Positioning of 3 patches

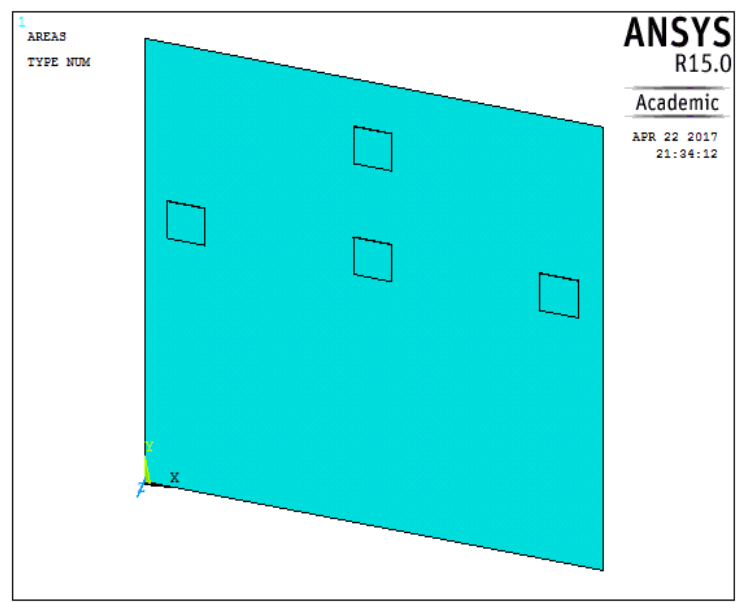

Fig. 7 Positioning of 4 patches 


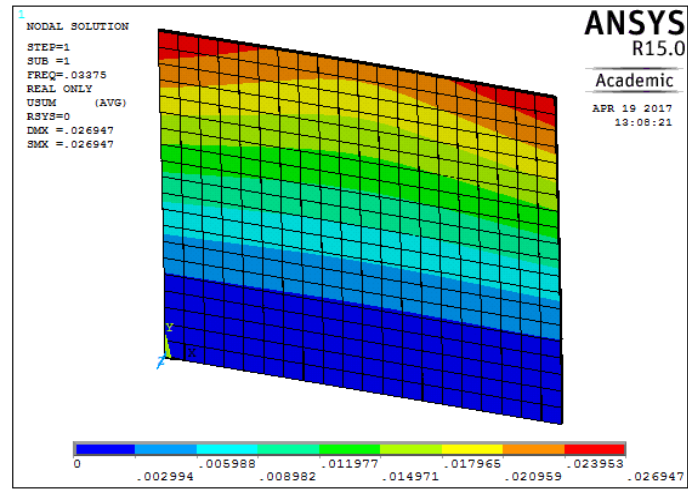

Fig. 8 Mode 1 in the case of $25 \times 25 \times 0.5 \mathrm{~mm}$ patch

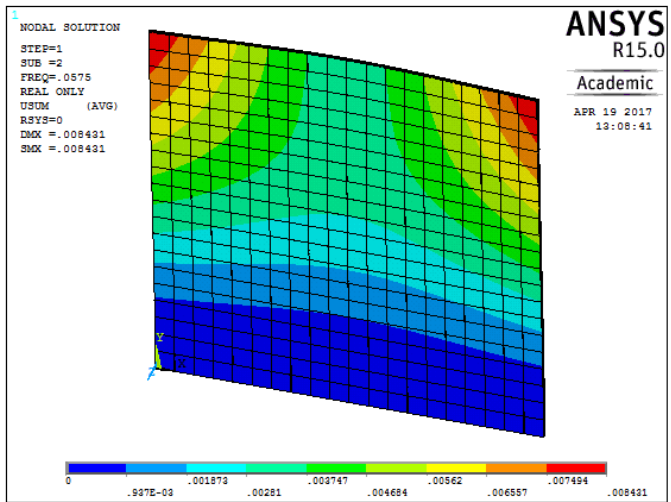

Fig. 9 Mode 2 in the case of $25 \times 25 \times 0.5 \mathrm{~mm}$ patch

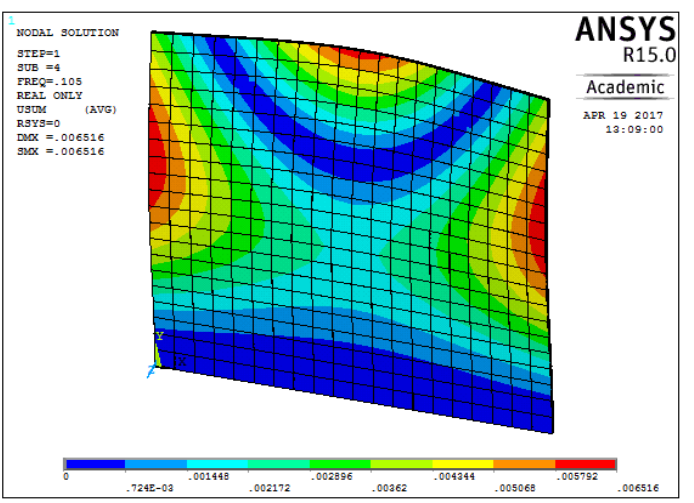

Fig. 10 Mode 3 in the case of $25 \times 25 \times 0.5 \mathrm{~mm}$ patch

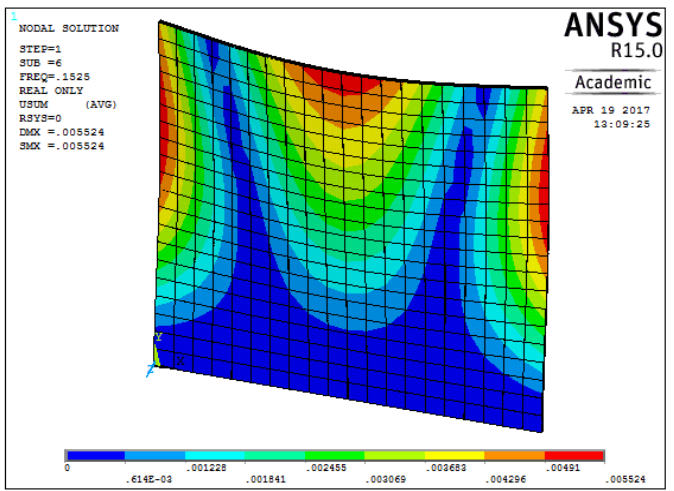

Fig. 11 Mode 4 in the case of $25 \times 25 \times 0.5 \mathrm{~mm}$ patch

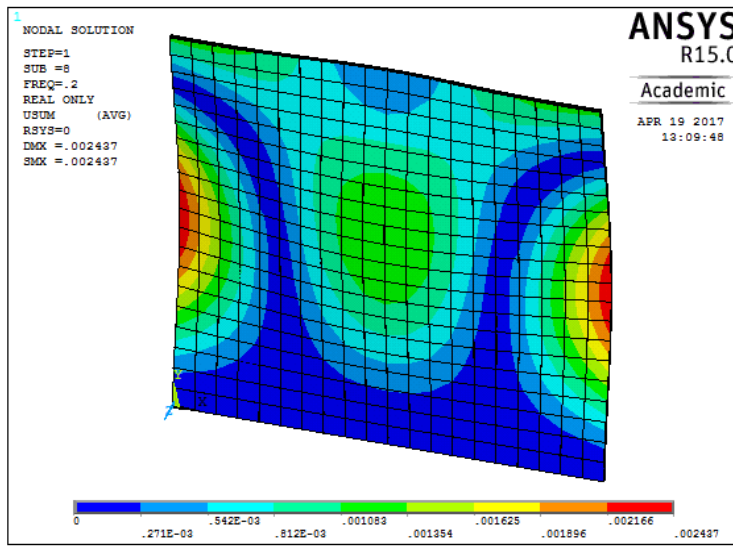

Fig. 12 Mode 5 in the case of $25 \times 25 \times 0.5 \mathrm{~mm}$ patch

Table 4. Nodal Displacements in case of $25 \times 25 \times 0.5$ mm patch.

\begin{tabular}{|c|c|c|c|c|}
\hline $\begin{array}{c}\text { Mode } \\
\text { Number }\end{array}$ & $\begin{array}{c}\text { One } \\
\text { Patch }\end{array}$ & $\begin{array}{c}\text { Two } \\
\text { Patches }\end{array}$ & $\begin{array}{c}\text { Three } \\
\text { Patches }\end{array}$ & $\begin{array}{c}\text { Four } \\
\text { Patches }\end{array}$ \\
\hline 1 & 26.947 & 23.38 & 9.866 & 4.671 \\
\hline 2 & 8.431 & 6.83 & 3.913 & 2.584 \\
\hline 3 & 6.516 & 8.731 & 12.5 & 3.163 \\
\hline 4 & 5.524 & 5.35 & 7.011 & 10.575 \\
\hline 5 & 2.437 & 3.595 & 6.644 & 10.751 \\
\hline
\end{tabular}

3.2 Analyzing the Laminated Composite plate based on the positional placement of patches:

In this case the Laminated Composite Plate is studied based on the positional placement of patches. For this three patches of dimensions, $25 \times 25 \times 0.5 \mathrm{~mm}$ is taken and positioned at different places in three different formations. The patch positioning is found to be more significant in the case of all frequency modes compared to number of patches which has its significance only in lower frequency modes. The patches positioning is more significant if they are placed around high strain areas. Moreover, the vibration attenuation is more significant if the patches are positioned at the initial positions where strains are developed. As the patch is positioned more towards the centre of the plate attenuation is more substantial and the displacement decreases.

The plate is of dimension $300 * 300 * 3 \mathrm{~m}$, so we considered $\mathrm{X}$-axis along the length $300 \mathrm{~mm}$ and Y-axis along the breadth $300 \mathrm{~mm}$ so it gives us coordinate plane positioning of patches applied on the surface. 
Table 5. Patch Coordinates for $25 \times 25 \times 0.5 \mathrm{~mm}$ patch in three different cases.

\begin{tabular}{|c|c|c|c|c|c|c|c|c|c|c|c|c|}
\hline $\begin{array}{l}\text { Patch } \\
\text { Number }\end{array}$ & \multicolumn{4}{|c|}{$\begin{array}{l}\text { Iteration } 1 \text { ( } \mathrm{x}, \mathrm{y} \text { coordinates of four } \\
\text { comers of patches) }\end{array}$} & \multicolumn{4}{|c|}{$\begin{array}{c}\text { Iteration } 2 \text { (x,y coordinates of four } \\
\text { comers of patches) }\end{array}$} & \multicolumn{4}{|c|}{$\begin{array}{c}\text { Iteration } 3 \text { (x,y coordinates of four } \\
\text { comers of patches) }\end{array}$} \\
\hline 1 & $\begin{array}{c}137.5, \\
245\end{array}$ & $\begin{array}{c}162.5 \\
245\end{array}$ & $\begin{array}{c}162.5 \\
270\end{array}$ & $\begin{array}{c}137.7= \\
270\end{array}$ & $\begin{array}{c}137.5 \\
245\end{array}$ & $\begin{array}{c}162.5, \\
240\end{array}$ & $\begin{array}{c}162.5, \\
270\end{array}$ & $\begin{array}{c}137.5, \\
270\end{array}$ & $\begin{array}{c}137.5, \\
245\end{array}$ & $\begin{array}{c}1642.5 \\
245\end{array}$ & $\begin{array}{c}162.5 \\
270\end{array}$ & $\begin{array}{c}137.5, \\
270\end{array}$ \\
\hline 2 & $\begin{array}{c}45, \\
137.5\end{array}$ & $\begin{array}{c}70, \\
137.5 \\
\end{array}$ & $\begin{array}{c}70, \\
162.5 \\
\end{array}$ & $\begin{array}{c}45, \\
162.5 \\
\end{array}$ & $\begin{array}{c}210 \\
137.5\end{array}$ & $\begin{array}{c}235 \\
137.5\end{array}$ & $\begin{array}{l}235 \\
162.5\end{array}$ & $\begin{array}{l}210 \\
162.5\end{array}$ & $\begin{array}{l}137.5 \\
137.5\end{array}$ & $\begin{array}{l}162.5 \\
137.5\end{array}$ & $\begin{array}{l}162.5 \\
162.5\end{array}$ & $\begin{array}{l}137.5 \\
162.5\end{array}$ \\
\hline 3 & $\begin{array}{c}225 \\
75\end{array}$ & $\begin{array}{c}250 \\
75\end{array}$ & $\begin{array}{l}250 \\
100\end{array}$ & $\begin{array}{l}225 \\
100\end{array}$ & $\begin{array}{c}90, \\
75\end{array}$ & $\begin{array}{c}115 \\
75\end{array}$ & $\begin{array}{l}115 \\
100\end{array}$ & $\begin{array}{l}90 \\
100\end{array}$ & $\begin{array}{c}137.5 \\
75\end{array}$ & $\begin{array}{c}162.5 \\
75\end{array}$ & $\begin{array}{c}162.5 \\
90\end{array}$ & $\begin{array}{c}137.5 \\
90\end{array}$ \\
\hline
\end{tabular}

Modal Diagrams for Iteration 1:

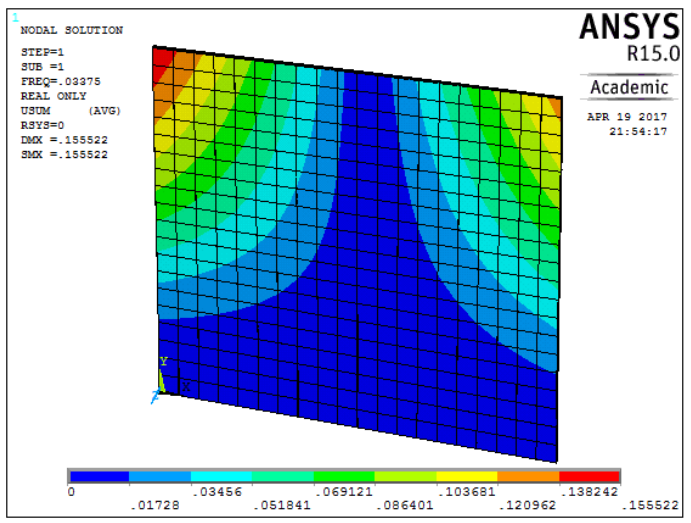

Fig. 13 Mode 1

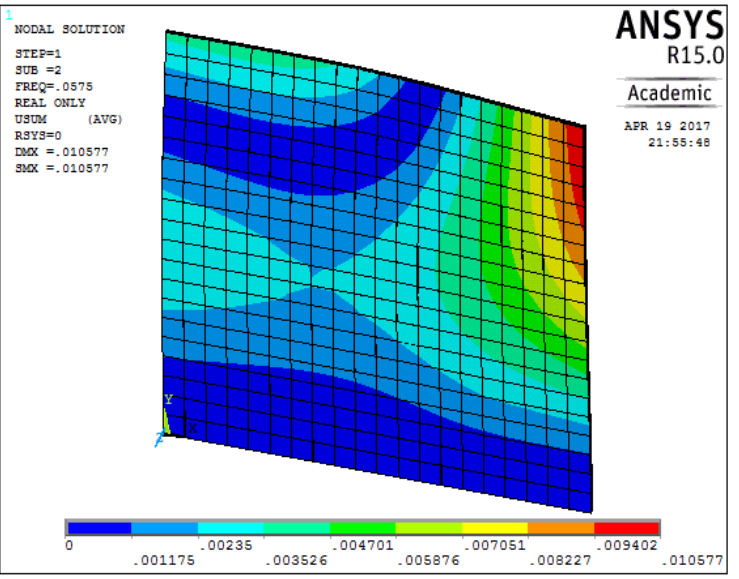

Fig. 14 Mode 2

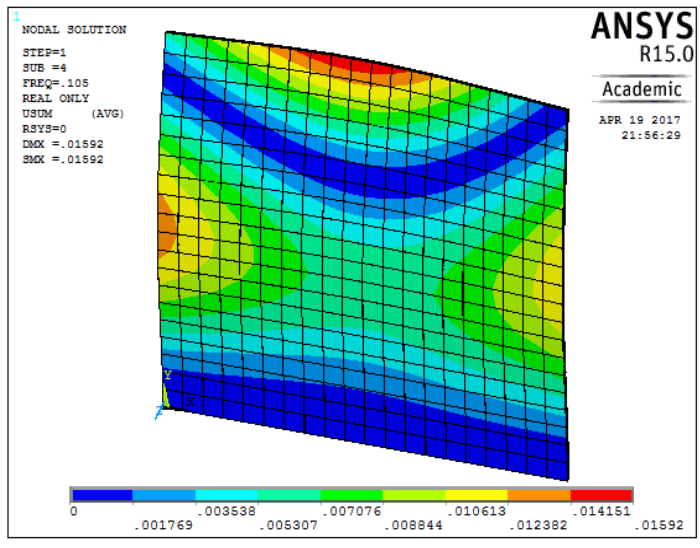

Fig. 15 Mode 3

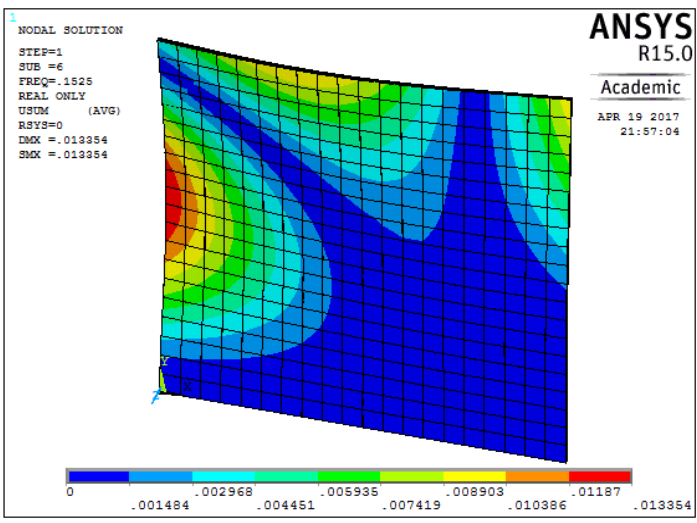

Fig 16 Mode 4

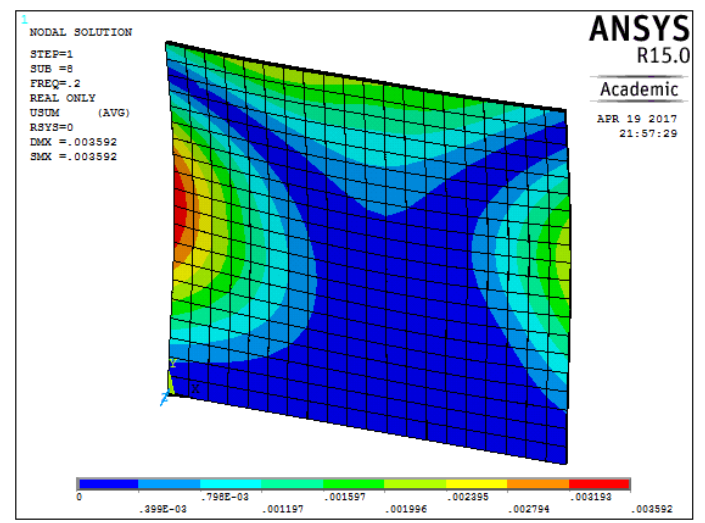

Fig. 17 Mode 5

Table 6. Positional influence of $25 \times 25 \times 0.5 \mathrm{~mm}$ patch in three different cases:

\begin{tabular}{|c|c|c|c|}
\hline $\begin{array}{c}\text { Mode } \\
\text { Number }\end{array}$ & Iteration 1 & Iteration 2 & Iteration 3 \\
\hline 1 & 155.522 & 84.065 & 9.866 \\
\hline 2 & 10.577 & 6.433 & 3.913 \\
\hline 3 & 15.92 & 14.025 & 12.5 \\
\hline 4 & 13.354 & 8.701 & 7.011 \\
\hline 5 & 3.592 & 4.62 & 6.644 \\
\hline
\end{tabular}

3.3 Analyzing the Laminated Composite plate based on patch size:

In this case, different patch sizes of $25 \times 25 \times 0.5 \mathrm{~mm}, 50 \times 50 \times 0.5 \mathrm{~mm}$ and $75 \times 75 \times 0.5 \mathrm{~mm}$ are positioned on the plate at same locations and the influence is observed. As the patch size increases the vibration is more attenuated and the 
displacement increases. But the more the size of the patch the less the number of patches of its category should be used because if more patches of higher dimension are placed the more they change the deflection in opposite directions.

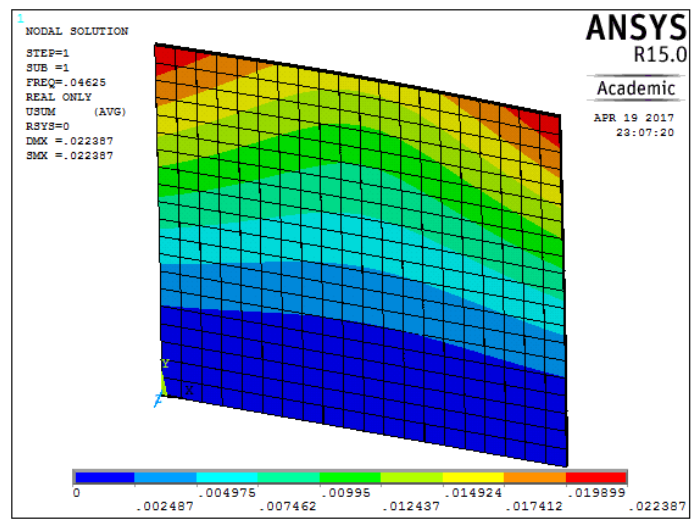

Fig. 18 Mode 1

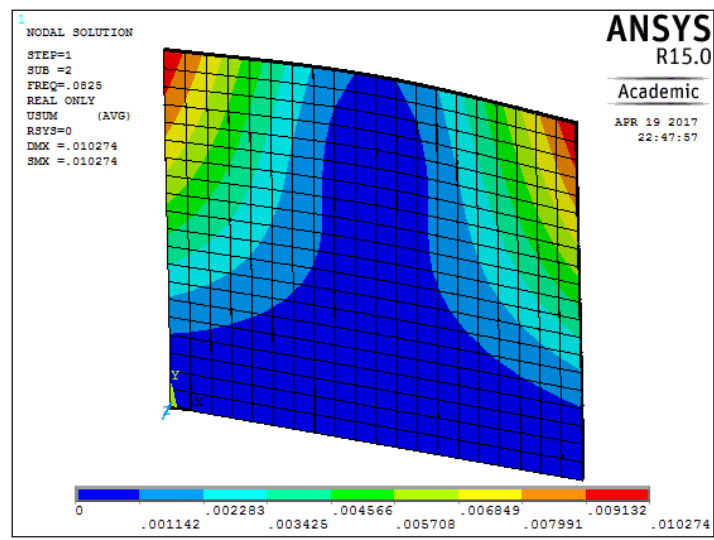

Fig. 19 Mode 2

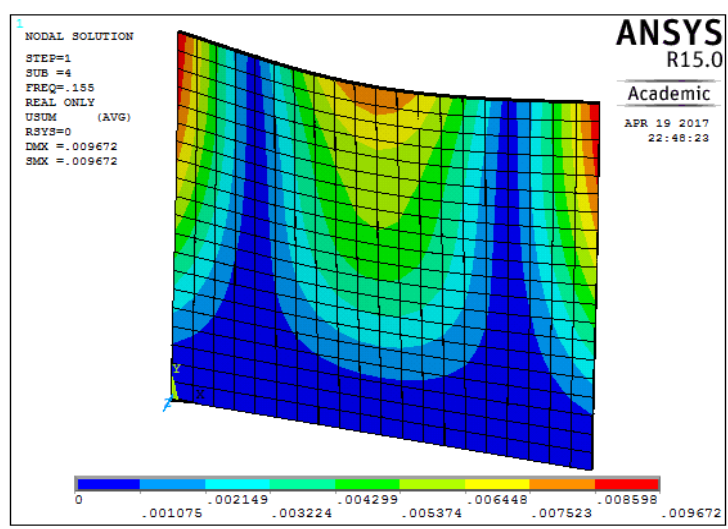

Fig. 20 Mode 3

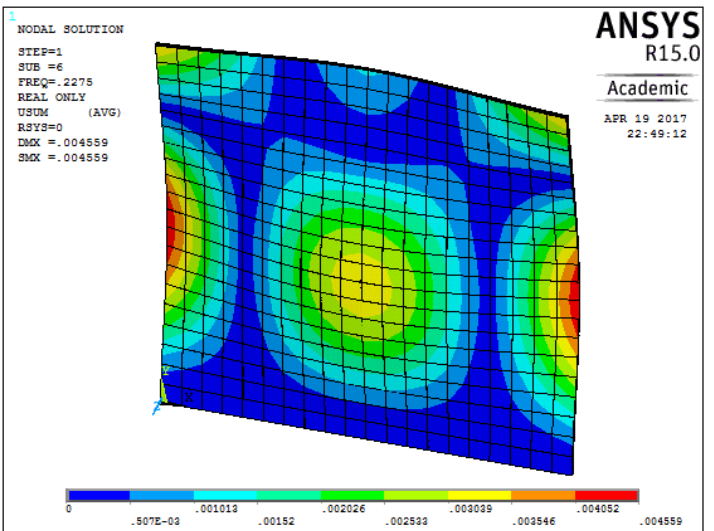

Fig. 21 Mode 4

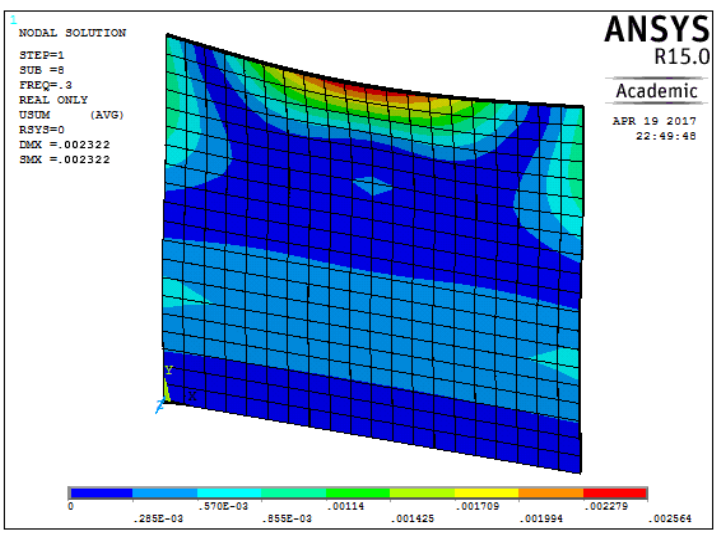

Fig. 22 Mode 5

Table 7. Patch size influence on Laminated composite plate:

\begin{tabular}{|c|c|c|c|}
\hline $\begin{array}{c}\text { Mode } \\
\text { Number }\end{array}$ & $\begin{array}{c}25 \times 25 \times 0.5 \\
\mathrm{~mm}\end{array}$ & $\begin{array}{c}50 \times 50 \times 0.5 \\
\mathrm{~mm}\end{array}$ & $\begin{array}{c}75 \times 75 \times 0.5 \\
\mathrm{~mm}\end{array}$ \\
\hline 1 & 26.947 & 22.387 & 19.417 \\
\hline 2 & 8.431 & 10.274 & 15.763 \\
\hline 3 & 6.516 & 9.672 & 9.963 \\
\hline 4 & 5.524 & 4.559 & 4.113 \\
\hline 5 & 2.437 & 2.322 & 2.167 \\
\hline
\end{tabular}

From the above three Tables 4, 6 and 7 the results are substantial and follow a certain pattern. As the patch is placed the displacements are reduced significantly, which in turn is a key indicator of vibration suppression.

\section{CONCLUSION}

Active vibration control is efficient compared to other techniques of passive and semiactive control. Moreover, the frequency modes it can cover significant is quite noticeable. As seen for active vibration control technique to be perfectly applied it involves mainly one significant approach involving position. The other two approaches of size factor and numerical influence are dependent upon the positioning of the patch. 
And the positioning shouldn't be exactly at the maximum bending curve it should be situated a bit lower. The position of the patch leads to variation in frequency and displacement. When multiple patches are concentrated around high strain areas the impact the patches apply to the plate/structure is more optimal. Instead of placing the patch away from the root position of strain developed if we place it right at the root position the deviation in displacement is quite more significant. The numerical influence is noticeable too but as discussed above if more patches of large sizes are concentrated on the plate the displacement depends on the size and stiffness of the overall plate and patch.

\section{REFERENCES}

[1]. Leitmann. G, Semiactive control for vibration attenuation, Journal of Intelligent Material Systems and Structures, 5(6), 1994, 841-846.

[2]. M.A. Trindade, A. Benjeddou, R. Ohayon, Piezoelectric active vibration control of damped sandwich beams, Journal of Sound and Vibration, 246(4), 2001, 653-677.

[3]. K. Ramkumar, S. Chandran, N. Ganesan, Finite Element Analysis of Composite Box Structure Containing Piezoelectric Actuators and Sensors for Active Vibration Control, SAE Techical Paper, 2009, (No. 2009-012147)

[4]. B. P. Baillargeon, S. S. Vel, Active vibration suppression of sandwich beams using piezoelectric shear actuators: experiments and numerical simulations, Journal of Intelligent Material Systems and Structures, 16(6), 2005, 517-530.

[5]. E. Bianchini, Active vibration control of automotive like panels, SAE Technical Paper, 2008, (No. 2008-36-0576).

[6]. B. Pletner, H. Abramovich, Adaptive suspension of vehicles using piezoelectric sensors, Journal of intelligent material systems and structures, 6(6), 1995, 744-756.

[7]. K. Chandrashekhara, A. N. Agarwal, Active vibration control of laminated composite plates using piezoelectric devices: a finite element approach, Journal of Intelligent Material Systems and Structures, 4(4), 1993, 496-508.

[8]. V. Gupta, M. Sharma, N. Thakur, Optimization criteria for optimal placement of piezoelectric sensors and actuators on a smart structure: a technical review, Journal of Intelligent Material Systems and Structures, 21(12), 2010, 1227-1243.

[9]. X. Q. Peng, K.Y. Lam, G.R. Liu, Active vibration control of composite beams with piezoelectrics: a finite element model with third order theory, Journal of sound and vibration, 209(4), 1998, 635-650.

[10]. S.S. Rafi, A. Sami, Finite Element Analysis of a Beam with Piezoelectrics using Third Order Theory-Part II Dynamic AnalysisActive Vibration Control, International Journal on Emerging Technologies, 2011, 135-139.

[11]. P.K. Gandhi, J. R. Mevada, A finite element model and active vibration control of composite beams with distributed piezoelectrics using third order theory, International Journal of Engineering Research and Applications (IJERA), 2013, 3(3).

[12]. M. A. Trindade, C.C. Pagani, L.P. Oliveira, Semi-modal active vibration control of plates using discrete piezoelectric modal filters, Journal of Sound and Vibration, 351, 2015, 17-28.

[13]. Y. Yaman, T. Caliskan, V. Nalbantoglu, E. Prasad, D. Waechter, Active vibration control of a smart plate, International Council of the Aeronautical Sciences, 2002, 8-13.

[14]. S. Raja, G. Prathap, P. K. Sinha, Active vibration control of composite sandwich beams with piezoelectric extension-bending and shear actuators, Smart Materials and Structures, 11(1), 2002, 63.

[15]. Z. C. Qiu, X. M. Zhang, H. X. Wu, H. H. Zhang, Optimal placement and active vibration control for piezoelectric smart flexible cantilever plate, Journal of Sound and Vibration, 301(3), 2007, 521-543.

[16]. E. Omidi, R. McCarty, S. N. Mahmoodi, Implementation of modified positive velocity feedback controller for active vibration control in smart structures, SPIE Smart Structures and Materials+ Nondestructive Evaluation and Health Monitoring (pp. 90571N-90571N), International Society for Optics and Photonics, 2014.

[17]. E. Varadarajan, M. Bhanusri, Design and simulation of unimorph piezoelectric energy harvesting system, COMSOL Conference in Bangalore, 2013, 17-18.

[18]. S. Daley, F. A. Johnson, J. B. Pearson, R. Dixon, Active vibration control for marine applications, Control Engineering Practice, 12(4), 2004, 465-474.

[19]. X. L. Huang, H. S. Shen, Nonlinear vibration and dynamic response of functionally graded plates in thermal environments, International Journal of 
Solids and Structures, 41(9), 2004, 24032427.

[20]. I. M. Díaz, E. Pereira, M. J. Hudson, P. Reynolds, Enhancing active vibration control of pedestrian structures using inertial actuators with local feedback control, Engineering Structures, 41, 2012, 157-166. 